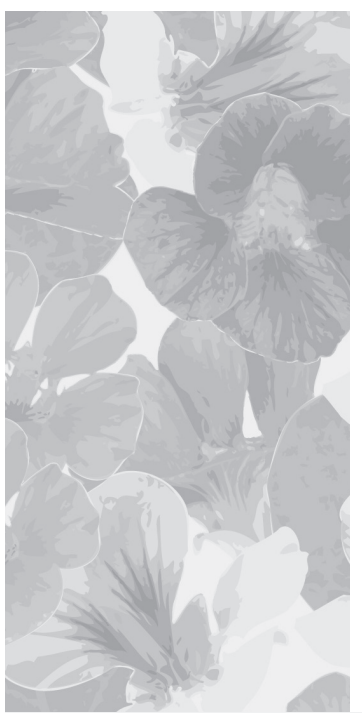

\title{
Analiza struktury abstraktów i treści artykułów przeglądowych z zakresu medycyny estetycznej i kosmetologii
}

\section{An analysis of the structure and content of the abstracts and main text in review articles in the field of aesthetic medicine and cosmetology}

\author{
Agnieszka Zabiegała, Barbara Potempa, Radosław Śpiewak \\ Zakład Dermatologii Doświadczalnej i Kosmetologii, Wydział Farmaceutyczny \\ Uniwersytet Jagielloński Collegium Medicum, Kraków \\ Estetol Med Kosmetol 2012; 2(3): 89-93 \\ DOI: http://dx.doi.org/10.14320/EMK.2012.018
}

\section{Streszczenie}

Prace przeglądowe stużą syntezie oraz systematyzowaniu wyników wielu badań w celu podsumowania aktualnego stanu wiedzy, zidentyfikowania „białych plam”, wytyczenia nowych kierunków badań, stworzenia algorytmów postępowania lub prezentacji nowych rozwiązań. Celem niniejszej pracy było zbadanie cech artykułów przeglądowych w polskich oraz zagranicznych czasopismach z zakresu medycyny estetycznej i kosmetologii. Materiat i metody: Na podstawie wyników kwerendy w internetowym katalogu Biblioteki Narodowej wytypowaliśmy aktualnie wydawane czasopisma polskie i zagraniczne, w których tytutach występowały ciągi znaków "estet” i „kosmet” oraz "cosmet” i „esthet” („aesthet”). Analizę zawęziliśmy do czasopism o charakterze naukowym wydanych w latach 2008-2011 roku oraz do petnotekstowych artykutów czasopism zagranicznych opublikowanych w języku angielskim indeksowanych w bazach PubMed, EMBASE lub Scopus. Ostatecznie analizą objęliśmy 4 czasopisma polskie oraz 5 czasopism zagranicznych, które tącznie zawierały 296 artykutów o charakterze przeglądowym (148 polskojęzycznych oraz 148 anglojęzycznych). W celu porównania przeanalizowaliśmy dodatkowo 2 czasopisma zagraniczne i 2 czasopisma polskie z dziedziny alergologii oraz dermatologii, które łącznie zawierały 282 artykuty o charakterze przeglądowym (93 polskojęzyczne oraz 189 anglojęzyczne). Artykuły przeanalizowaliśmy pod kątem występowania cech charakterystycznych dla struktury artykutu przeglądowego. Wyniki: Spośród 54 przeanalizowanych cech tylko jedna (obecność streszczenia pracy) była spełniona w blisko 100\% artykułów, zarówno polsko-, jak i anglojęzycznych. Spośród przeanalizowanych 148 artykutów polskojęzycznych z zakresu medycyny estetycznej, tylko 5,2\% zawierało wzmianki o metodzie doboru piśmiennictwa (sposób i kryteria wyszukiwania w bazach danych, zastosowane słowa kluczowe, typu badań włączonych do analizy oraz kryteriów selekcji prac pod względem języka i daty publikacji). W artykułach anglojęzycznych informacje dotyczące metod doboru literatury podawano częściej $(10,8-21,6 \%$ analizowanych artykutów, $p<0,001)$. Charakterystyczną wadą stwierdzaną w 9,5\% artykutów polskojęzycznych był brak cytowania źródeł w tekście oraz brak piśmiennictwa. Wnioski: Większość artykutów z zakresu medycyny estetycznej i kosmetologii publikowanych jako przeglądowe ma w istocie charakter niesystematycznych i niestrukturyzowanych esejów, co stawia pod znakiem zapytania ich wartość naukową.

Stowa kluczowe: artykut przeglądowy, przegląd literatury, przegląd systematyczny, medycyna estetyczna, kosmetologia

\begin{abstract}
Review articles serve the synthesis and systematization of results from numerous studies in order to summarize the current state of knowledge, chart new directions for research, and create algorithms for conduct or propose new solutions. Aim: To investigate the features of review articles in Polish and foreign journals in the field of aesthetic medicine and cosmetology. Material and methods: Based on the results of a query in the online catalogue of the National Library, we selected Polish and foreign journals with titles containing the Polish terms: 'estet', 'kosmet', 'cosmet', 'aesthet' ('esthet'). The analysis covered all Polish scientific journals in this field published between 2008-2011, as well as English-language journals that were indexed in the databases PubMed, EMBASE or Scopus, and available in full-text at our university's library. Finally, the analysis comprised four Polish and five foreign journals containing a total of 296 review articles (148 in Polish and 148 in English). As a reference, we analyzed two Polish and two international journals in the field of allergy and dermatology, with 282 review articles (93 in Polish and 189 in English). The articles were analyzed for the presence of features characteristic of a review article. Results: Of the 54 analyzed features, only one (the presence of an abstract) was fulfilled in nearly $100 \%$ articles, both Polish- and English-language. Of the 148 Polish-language reviews on aesthetic medicine or cosmetology, only $5.2 \%$ contained any mention of the method of collecting the source literature (method and criteria for searching databases, key words used, types of studies selected for review, language or date of publication). English-language articles contained this information more often (10.8-21.6\% analyzed articles, $\mathrm{p}<0.001)$. Conclusions: Most of the articles in the field of aesthetic medicine and cosmetology published as reviews essentially are non-systematic, unstructured essays, which brings their scientific value into question.
\end{abstract}

Keywords: review article, literature review, systematic review, aesthetic medicine, cosmetology

Copyright $\odot 2012$ the Authors (text) and Radosław Śpiewak (layout \& journal compilation). All rights reserved. 
Prace przeglądowe służą syntezie oraz systematyzowaniu wyników wielu badań w celu podsumowania aktualnego stanu wiedzy, zidentyfikowania „białych plam”, wytyczenia kierunków nowych badań, stworzenia algorytmów postępowania lub prezentowania nowych rozwiązań, co ułatwiłoby orientację w danym zagadnieniu nowym adeptom, a ekspertom pomogłoby zreasumować i uporządkować swoją wiedzę. Część artykułów przeglądowych wydaje się jednak nie spełniać tego zadania.

\section{Cel}

Celem niniejszej pracy była analiza występowania pożądanych cech artykułów przeglądowych w czasopismach polskich oraz zagranicznych z zakresu medycyny estetycznej oraz kosmetologii.

\section{Materiat i metody}

Na podstawie wyników kwerendy w internetowym katalogu Biblioteki Narodowej wytypowaliśmy aktualnie wydawane czasopisma polskie i zagraniczne, w których tytułach występowały ciągi znaków „estet” i „kosmet” oraz „,cosmet” i ,esthet” (,,aesthet”). Analizę zawęziliśmy do czasopism o charakterze naukowym wydanych od 2008 do 2011 roku oraz do pełnotekstowych artykułów z czasopism zagranicznych dostępnych online, opublikowanych w języku angielskim oraz indeksowanych w bazach PubMed, EMBASE lub Scopus. Ostatecznie analizą objęliśmy 5 czasopism zagranicznych z zakresu medycyny estetycznej i kosmetologii (Aesthetic Plastic Surgery Journal, Clinical Cosmetic and Investigational Dermatology, International Journal of Cosmetic Science, Journal of Cosmetic Dermatology oraz Journal of Plastic Reconstructive and Aesthetic Surgery) oraz 4 czasopisma polskie (Academy of Aesthetic and Anti-Aging Medicine, Dermatologia Estetyczna, Estetologia Medyczna i Kosmetologia oraz Polish Journal of Cosmetology) dostępne online lub w wersji papierowej w bibliotece medycznej Uniwersytetu Jagiellońskiego. Czasopisma z zakresu medycyny estetycznej i kosmetologii łącznie zawierały 296 artykułów o charakterze przeglądowym (148 polskojęzycznych oraz 148 anglojęzycznych). W celu porównania analizą objęliśmy dodatkowo 2 czasopisma zagraniczne (Allergy, Journal of Investigative Dermatology) oraz 2 czasopisma polskie (Alergia Astma Immunologia, Przegląd Dermatologiczny) z zakresu alergologii oraz dermatologii. Podstawą wyboru czasopism odniesienia był dostęp online do pełnotekstowych artykułów. Wybrane czasopisma $\mathrm{z}$ dziedzin alergologii oraz dermatologii łącznie zawierały 282 artykuły o charakterze przeglądowym (93 polskojęzyczne i 189 anglojęzyczne). Wyszukane artykuły przeanalizowaliśmy pod kątem występowania cech charakterystycznych dla dobrego artykułu przeglądowego, wytypowanych na podstawie prac dotyczących metodologii pisania artykułów przeglądowych. Prace te zidentyfikowano w bazie PubMed w sierpniu 2012 r. za pomocą kombinacji słów kluczowych „review”, „article”, „systematic review”, „,narrative review”, „literature review" oraz artykułów wskazywanych przez bazy bibliograficzne, jako „spokrewnione tematycznie” (related articles).

\section{Wyniki}

Spośród 54 przeanalizowanych, tylko jedna cecha (streszczenie pracy) była obecna w prawie wszystkich artykułach przeglądowych z zakresu medycyny estetycznej i kosmetologii, zarówno polskich (97,3\%) jak i zagranicznych (100\%). Spośród przeanalizowanych 148 artykułów polskojęzycznych $89,8 \%$ nie zawierało wzmianki na temat metody doboru piśmiennictwa (sposobu i kryteriów przeszukiwania baz danych, zastosowanych słów kluczowych, rodzaju cytowanych w pracy badań oraz kryteriów selekcji prac pod względem języka i daty publikacji). W artykułach anglojęzycznych informacja na temat metod doboru literatury występowała nieco częściej, to jest w 10,8-21,6\% artykułów w zależności od analizowanej cechy szczegółowej. Charakterystyczną cechą obecną w $9,5 \%$ artykułów polskojęzycznych był brak cytowania źródeł w tekście oraz brak spisu piśmiennictwa. Praktyki tej nie zaobserwowaliśmy w analizowanych czasopismach zagranicznych. Częstość występowania postulowanych cech dobrego artykułu przeglądowego w analizowanych artykułach przeglądowych przedstawia tabela 1 (struktura i zawartość streszczeń) oraz tabela 2 (struktura i treść pełnego tekstu pracy).

\section{Dyskusja}

Podstawę rozwoju danej dziedziny naukowej, lecz także awansu pracowników nauki stanowią artykuły oryginalne [1]. Jednak każdego roku publikowanych jest około 2 milionów artykułów w ponad 20 tys. czasopism biomedycznych, w związku z czym istnieje potrzeba syntezy i spójnej prezentacji wyników badań z określonych obszarów nauki. Wyniki pojedynczych oryginalnych prac badawczych rzadko mogą być wykorzystane przez niespecjalistów, a lukę tę mogą zapełnić rzetelne przeglądy systematyczne [2]. Artykuły przeglądowe dzielimy na narrative/literature review (,narracyjny” lub subiektywny przegląd piśmiennictwa) oraz systematic review (przegląd systematyczny). Przeglądy „narracyjne" powinny być zastrzeżone dla ekspertów w danej dziedzinie, a mimo to należy pamiętać, że ze względu na nieustrukturyzowaną formę i brak ścisłej metodologii wyboru literatury przedstawione treści mogą pozostawać pod wpływem uprzedzeń lub zbytniego entuzjazmu autora. Przeciwwagę może tu stanowić przegląd systematyczny, którego wnioski wynikają z analizy wykonanej według ściśle określonej metodologii i kryteriów włączenia lub wykluczenia literatury 
Tabela 1. Analiza struktury i zawartości streszczeń artykułów przeglądowych z czasopism objętych analizą

\begin{tabular}{|c|c|c|c|c|c|c|c|}
\hline L.p. & Analizowane cechy & $\begin{array}{c}\text { Czasopisma zzakresu medy- } \\
\text { cyny estetycznej i kosmetologii } \\
\text {-artykuly anglojęzyczme } \\
\text { (N=148) }\end{array}$ & $\begin{array}{c}\text { Czasopisma zzakresu medy- } \\
\text { cyny estetycznej i kosmetologii } \\
\text {-artykuly polskojezycze } \\
\text { (N=148) }\end{array}$ & $\begin{array}{l}\text { Czasopisma zzakresu } \\
\text { alergologii oraz dermatologii- } \\
\text { artykuly anglojęzyczne } \\
(\mathrm{N}=189)\end{array}$ & $\begin{array}{l}\text { Czasopisma z zakresu } \\
\text { alergologii oraz dermatologii- } \\
\text { artykuły polskojęzyczne } \\
(\mathrm{N}=93)\end{array}$ & $\chi^{2}$ & $\mathbf{p}$ \\
\hline 1. & Obecność streszczenia & $100 \%(148)$ & $97,3 \%(144)$ & $98,7 \%(187)$ & $100 \%(93)$ & 3,579 & 0,310 \\
\hline 2. & Streszczenie w języku polskim & - & $97,3 \%(144)$ & - & $100 \%(93)$ & 1,168 & 0,280 \\
\hline 3. & Streszczenie w języku angielskim & $100 \%(148)$ & $94,4 \%(136)$ & $98,7 \%(187)$ & $100 \%(93)$ & 22,995 & $<0,001$ \\
\hline \multicolumn{8}{|c|}{ Struktura streszczenia (wyodrębnienie śródtytulami poszczególnych części) } \\
\hline 4. & Wyodrębnienie śródtytułem wstępu & $17,6 \%(26)$ & $7,6 \%(11)$ & $4,3 \%(8)$ & $5,4 \%(5)$ & 18,937 & $<0,001$ \\
\hline 5. & Wyodrębnienie śródtytułem celu pracy & $6,1 \%(9)$ & $11,8 \%(17)$ & $1,1 \%(2)$ & $2,2 \%(2)$ & 17,698 & $<0,001$ \\
\hline 6. & $\begin{array}{l}\text { Wyodrębnienie śródtytułem materiału } \\
\text { i metod }\end{array}$ & $17,6 \%(26)$ & $7,6 \%(11)$ & $5,4 \%(10)$ & $0,0 \%(0)$ & 25,284 & $<0,001$ \\
\hline 7. & Wyodrębnienie śródtytułem wyników & $14,2 \%(21)$ & $4,9 \%(7)$ & $5,4 \%(10)$ & $1,1 \%(1)$ & 16,857 & $<0,001$ \\
\hline 8. & Wyodrębnienie śródtytułem wniosków & $14,2 \%(21)$ & $8,3 \%(12)$ & $5,4 \%(10)$ & $0,0 \%(0)$ & 16,267 & $<0,001$ \\
\hline \multicolumn{8}{|c|}{ Zawartość streszczenia } \\
\hline 9. & $\begin{array}{l}\text { Opisanie tła, przesłanek dokonania } \\
\text { analizy }\end{array}$ & $93,9 \%(139)$ & $25,7 \%(37)$ & $97,8 \%(183)$ & $0,0 \%(0)$ & 395,247 & $<0,001$ \\
\hline 10. & Sformułowanie celu analizy & $61,5 \%(91)$ & $10,4 \%(15)$ & $44,4 \%(83)$ & $0,0 \%(0)$ & 141,667 & $<0,001$ \\
\hline 11. & $\begin{array}{l}\text { Opis metod wyszukiwania literatury } \\
\text { źródłowej (np. PubMed, Scopus, Embase, } \\
\text { ręczne przeszukiwanie czasopism) }\end{array}$ & $16,2 \%(24)$ & $0,7 \%(1)$ & $8,6 \%(16)$ & $0,0 \%(0)$ & 31,548 & $<0,001$ \\
\hline 12. & $\begin{array}{l}\text { Opis doboru słów kluczowych na podsta- } \\
\text { wie których były wyszukiwane artykuły }\end{array}$ & $4.1 \%(6)$ & $0,0 \%(0)$ & $4,3 \%(8)$ & $0,0 \%(0)$ & 7,078 & 0,069 \\
\hline 13. & $\begin{array}{l}\text { Informacja, jaki rodzaj artykułów/badań } \\
\text { został włączony lub wykluczony z analizy }\end{array}$ & $10,1 \%(15)$ & $0,0 \%(0)$ & $7,5 \%(14)$ & $0,0 \%(0)$ & 19,604 & $<0,001$ \\
\hline 14. & $\begin{array}{l}\text { Informacja, z jakiego okresu artykuły } \\
\text { zostały objęte analizą }\end{array}$ & $6,8 \%(10)$ & $0,7 \%(1)$ & $9,7 \%(18)$ & $0,0 \%(0)$ & 16,641 & $<0,001$ \\
\hline 15. & $\begin{array}{l}\text { Informacja na temat języka objętych } \\
\text { analizą artykułów }\end{array}$ & $4,7 \%(7)$ & $0,7 \%(1)$ & $2,2 \%(4)$ & $0,0 \%(0)$ & 5,856 & 0,118 \\
\hline 16. & $\begin{array}{l}\text { Występowanie tylko } 1 \mathrm{z} \text { cech wymie- } \\
\text { nionych w pozycjach } 11-15\end{array}$ & $6,8 \%(10)$ & $2,1 \%(3)$ & $3,2 \%(6)$ & $0,0 \%(0)$ & 7,187 & 0,066 \\
\hline 17. & $\begin{array}{l}\text { Występowanie } 2 \text { cech z wymienionych } \\
\text { w pozycjach } 11-15\end{array}$ & $4,1 \%(6)$ & $0,0 \%(0)$ & $2,8 \%(5)$ & $0,0 \%(0)$ & 5,708 & 0,127 \\
\hline 18. & $\begin{array}{l}\text { Występowanie } 3 \text { cech } \mathrm{z} \text { wymienionych } \\
\text { w pozycjach } 11-15\end{array}$ & $3,4 \%(5)$ & $0,0 \%(0)$ & $6,5 \%(12)$ & $0,0 \%(0)$ & 11,943 & 0,007 \\
\hline 19. & $\begin{array}{l}\text { Występowanie } 4 \text { cech z wymienionych } \\
\text { w pozycjach } 11-15\end{array}$ & $3,4 \%(5)$ & $0,0 \%(0)$ & $1,1 \%(2)$ & $0,0 \%(0)$ & 5,456 & 0,141 \\
\hline 20. & $\begin{array}{l}\text { Występowanie } 5 \text { cech } \mathrm{z} \text { wymienionych } \\
\text { w pozycjach } 11-15\end{array}$ & $0,7 \%(1)$ & $0,0 \%(0)$ & $0,0 \%(0)$ & $0,0 \%(0)$ & 1,273 & 0,735 \\
\hline 21. & $\begin{array}{l}\text { Nie występowanie ani jednej z cech } \\
\text { wymienionych w pozycjach } 11-15\end{array}$ & $81,8 \%(121)$ & $97,9 \%(141)$ & $86,6 \%(162)$ & $100 \%(93)$ & 25,483 & $<0,001$ \\
\hline 22. & $\begin{array}{l}\text { Opis sposobu ostatecznego wyboru przez } \\
\text { autora prac źródłowych do artykułu } \\
\text { przeglądowego }\end{array}$ & $8,1 \%(12)$ & $0,0 \%(0)$ & $6,5 \%(12)$ & $0,0 \%(0)$ & 15,105 & 0,002 \\
\hline 23. & Przedstawienie wyników analizy & $20,9 \%(31)$ & $6,3 \%(9)$ & $10,7 \%(20)$ & $1,1 \%(1)$ & 26,416 & $<0,001$ \\
\hline 24. & Przedstawienie wniosków & $33,8 \%(50)$ & $8,3 \%(12)$ & $30,5 \%(57)$ & $0,0 \%(0)$ & 61,191 & $<0,001$ \\
\hline
\end{tabular}

źródłowej, w celu zminimalizowania subiektywizmu [3].

Przegląd systematyczny powinien zawierać szczegółowy opis wykorzystanych baz danych bibliograficznych (np. Medline, Embase, Google Scholar, PsychINFO, Eric, Cochrane Library, Sociological Abstracts), zastosowanych słów kluczowych, rodzajów badań włączonych do analizy, ram czasowych włączenia oraz ewentualnych ograniczeń w odniesieniu do języka publikacji. Każda z baz bibliograficznych pracuje w innym systemie wyszukiwania literatury i obejmuje zbiór innych czasopism, dlatego korzystając $\mathrm{z}$ różnych wyszukiwarek lub przeszukując ręcznie czasopisma można zidentyfikować różne artykuły źródłowe, co może wpłynąć na ostateczne wyniki analizy [4-7]. Oprócz metodologii wyszukiwania i selekcji literatury źródłowej do analiz, kolejnym istotnym elementem jest ustrukturyzowanie pracy [8], w tym jasne sformułowanie jej zakresu oraz określenie rodzaju opracowanego przeglądu. Podanie w tytule jego charakteru - „systematic review" lub „narrative/literature review” poinformuje czytelnika, z jakim rodzajem analizy będzie miał do czynienia [9]. Niestety, jak pokazują nasze wyniki, takie określenie charakteru pracy przeglądowej pojawiło się w tytule zaledwie jednego $(0,7 \%)$ spośród wszystkich przeanalizowanych artykułów polskojęzycznych. W artykułach przeglądowych anglojęzycznych charakter przeglądowy deklarowano znacznie częściej, bo w tytułach aż 29,1\% analizowanych prac, w tej grupie dookreślenie ,systematic” lub „narative/literature” pojawiło się w 12,8\% prac (19 artykułów).

Zadaniem przeglądu systematycznego jest wskazywanie luk w dotychczasowych badaniach, identyfikacja nowych kierunków, formułowanie nowych hipotez, systematyzowanie aktualnej wiedzy [2]. Guilford zwraca uwagę na trudności w napisaniu pracy przeglądowej, z jakimi borykają się początkujący naukowcy czy studenci. Szczególną trudność stanowi właściwy dobór i opis metodologii pisania pracy oraz sformułowanie 
celu pracy, co determinuje poprawność wyciągniętych wniosków [10]. Nie wolno zapominać, że dla wartości publikacji przeglądowej istotna jest również liczba artykułów źródłowych, która zdaniem Gasparyana i wsp. powinna mieścić się w zakresie do 50 do 100 [9]. $\mathrm{W}$ analizowanych przez nas artykułach anglojęzycznych z zakresu estetologii średnia liczba prac źródłowych $(66,1)$ mieściła się w postulowanym zakresie, natomiast w przypadku artykułów polskojęzycznych (średnio 26,7 artykułów źródłowych) okazała się ona istotnie niższa $(\mathrm{p}<0,001)$.

Wyniki zbliżone do przedstawionych w niniejszej pracy uzyskała autorka analizy publikacji przeglądowych w czasopismach medycznych z lat 1985-1986 [11]: W przeanalizowanych przez nią artykułach rzadko opi-

Tabela 2. Analiza struktury i treści w obrębie głównego tekstu analizowanych artykułów przeglądowych

\begin{tabular}{|c|c|c|c|c|c|c|c|}
\hline L.p. & Analizowane cechy & $\begin{array}{c}\text { Czasopisma zzakresu medy- } \\
\text { cyny estetycznej i kosmetologii } \\
\text {-artykuly anglojezyczne } \\
(\mathrm{N}=148)\end{array}$ & $\begin{array}{c}\text { Czasopisma zzakresu medy- } \\
\text { cyny estetyczmej i kosmetologii } \\
\text {-artykuly polskojezyczene } \\
\text { (N=148) }\end{array}$ & $\begin{array}{l}\text { Czasopisma zzakresu } \\
\text { alergologii oraz dermatologii- } \\
\text { artykuly anglojęzyczne } \\
(\mathrm{N}=189)\end{array}$ & $\begin{array}{l}\text { Czasopisma z zakresu } \\
\text { alergologii oraz dermatologii- } \\
\text { artykuly polskojęzyczne } \\
(\mathrm{N}=93)\end{array}$ & $x^{2}$ & $\mathbf{p}$ \\
\hline 1. & $\begin{array}{l}\text { Zawarta w tytule informacja, że jest to } \\
\text { artykuł przeglądowy }\end{array}$ & $29,1 \%(43)$ & $0,7 \%(1)$ & $8,5 \%(16)$ & $2,2 \%(2)$ & 71,660 & $<0,001$ \\
\hline 2. & $\begin{array}{l}\text { Zaznaczenie, że jest to przegląd lite- } \\
\text { ratury/narracyjny (literature review/ } \\
\text { narrative review) }\end{array}$ & $6,8 \%(10)$ & $0,0 \%(0)$ & $0,0 \%(0)$ & $2,2 \%(2)$ & 19,078 & $<0,001$ \\
\hline 3. & $\begin{array}{l}\text { Zaznaczenie, że jest to przegląd syste- } \\
\text { matyczny (systematic review) }\end{array}$ & $6,1 \%(9)$ & $0,7 \%(1)$ & $1,1 \%(2)$ & $0,0 \%(0)$ & 12,222 & 0,007 \\
\hline 4. & $\begin{array}{l}\text { Użycie sformułowania artykuł } \\
\text { przeglądowy bez dookreślenia (review } \\
\text { article) }\end{array}$ & $16,2 \%(24)$ & $0,0 \%(0)$ & $7,4 \%(14)$ & $0,0 \%(0)$ & 35,847 & $<0,001$ \\
\hline \multicolumn{8}{|c|}{ Struktura artykułu (wyodrębnienie śródtytulami poszczególnych części artykułu) } \\
\hline 5. & Wyodrębnienie śródtytułem wstępu & $51,4 \%(76)$ & $43,2 \%(64)$ & $55,6 \%(105)$ & $72,0 \%(67)$ & 19,683 & $<0,001$ \\
\hline 6. & Wyodrębnienie śródtytułem celu pracy & $1,4 \%(2)$ & $3,4 \%(5)$ & $0,0 \%(0)$ & $3,2 \%(3)$ & 4,386 & 0,222 \\
\hline 7. & $\begin{array}{l}\text { Wyodrębnienie śródtytułem materiałów } \\
\text { i metod }\end{array}$ & $22,3 \%(33)$ & $4,1 \%(6)$ & $9,5 \%(18)$ & $0,0 \%(0)$ & 38,446 & $<0,001$ \\
\hline 8. & Wyodrębnienie śródtytułem wyników & $17,6 \%(26)$ & $6,1 \%(9)$ & $10,1 \%(19)$ & $0,0 \%(0)$ & 23,377 & $<0,001$ \\
\hline 9. & Wyodrębnienie śródtytułem wniosków & $55,4 \%(82)$ & $61,5 \%(91)$ & $57,7 \%(109)$ & $58,3 \%(56)$ & 1,293 & 0,731 \\
\hline \multicolumn{8}{|c|}{ Treść artykułu } \\
\hline 10. & $\begin{array}{l}\text { Opisanie tła, przesłanek dokonania } \\
\text { analizy }\end{array}$ & $95,3 \%(141)$ & $62,2 \%(92)$ & $97,9 \%(185)$ & $36,6 \%(34)$ & 179,683 & $<0,001$ \\
\hline 11. & Sformułowanie celu analizy & $46,6 \%(69)$ & $3,4 \%(5)$ & $59,8 \%(113)$ & $2,2 \%(2)$ & 168,763 & $<0,001$ \\
\hline 12. & $\begin{array}{l}\text { Opis metod wyszukiwania literatury } \\
\text { źródłowej (np. PubMed, Scopus, Embase, } \\
\text { ręczne przeszukiwanie czasopism) }\end{array}$ & $21,6 \%(32)$ & $2,0 \%(3)$ & $15,4 \%(29)$ & $0,0 \%(0)$ & 40,633 & $<0,001$ \\
\hline 13. & $\begin{array}{l}\text { Opis doboru słów kluczowych na podsta- } \\
\text { wie których były wyszukiwane artykuły }\end{array}$ & $18,2 \%(27)$ & $2,0 \%(3)$ & $13,8 \%(26)$ & $0,0 \%(0)$ & 32,518 & $<0,001$ \\
\hline 14. & $\begin{array}{l}\text { Informacja, jakie artykuły/badania został } \\
\text { włączone lub wykluczone z analizy }\end{array}$ & $20,3 \%(30)$ & $3,4 \%(5)$ & $16,4 \%(31)$ & $0,0 \%(0)$ & 34,334 & $<0,001$ \\
\hline 15. & $\begin{array}{l}\text { Informacja, z jakiego okresu artykuły } \\
\text { zostały objęte analizą }\end{array}$ & $15,5 \%(23)$ & $2,7 \%(4)$ & $10,1 \%(19)$ & $0,0 \%(0)$ & 23,345 & $<0,001$ \\
\hline 16. & $\begin{array}{l}\text { Informacja na temat języka objętych } \\
\text { analizą artykułów }\end{array}$ & $10,8 \%(16)$ & $0,7 \%(1)$ & $6,3 \%(12)$ & $0,0 \%(0)$ & 18,590 & $<0,001$ \\
\hline 17. & $\begin{array}{l}\text { Występowanie tylko } 1 \mathrm{z} \text { cech wymie- } \\
\text { nionych w pozycjach } 12-16\end{array}$ & $1,4 \%(2)$ & $2,0 \%(3)$ & $1,9 \%(4)$ & $0,0 \%(0)$ & 0,771 & 0,856 \\
\hline 18. & $\begin{array}{l}\text { Występowanie } 2 \text { cech z wymienionych } \\
\text { w pozycjach } 12-16\end{array}$ & $1,4 \%(2)$ & $0,0 \%(0)$ & $0,0 \%(0)$ & $0,0 \%(0)$ & 2,048 & 0,562 \\
\hline 19. & $\begin{array}{l}\text { Występowanie } 3 \text { cech z wymienionych } \\
\text { w pozycjach } 12-16\end{array}$ & $5,4 \%(8)$ & $0,0 \%(0)$ & $4,3 \%(9)$ & $0,0 \%(0)$ & 9,343 & 0,025 \\
\hline 20. & $\begin{array}{l}\text { Występowanie } 4 \text { cech z wymienionych } \\
\text { w pozycjach } 12-16\end{array}$ & $8,1 \%(12)$ & $1,4 \%(2)$ & $4,3 \%(9)$ & $0,0 \%(0)$ & 10,614 & 0,014 \\
\hline 21. & $\begin{array}{l}\text { Występowanie } 5 \text { cech z wymienionych } \\
\text { w pozycjach } 12-16\end{array}$ & $6,1 \%(9)$ & $0,7 \%(1)$ & $5,3 \%(10)$ & $0,0 \%(0)$ & 8,727 & 0,033 \\
\hline 22. & $\begin{array}{l}\text { Nie występowanie ani jednej z cech } \\
\text { wymienionych w pozycjach } 12-16\end{array}$ & $77,7 \%(115)$ & $95,9 \%(142)$ & $83,1 \%(157)$ & $100 \%(93)$ & 36,692 & $<0,001$ \\
\hline 23. & $\begin{array}{l}\text { Opis sposobu ostatecznego wyboru przez } \\
\text { autora prac źródłowych do artykułu } \\
\text { przeglądowego }\end{array}$ & $16,9 \%(25)$ & $1,4 \%(2)$ & $11,6 \%(22)$ & $0,0 \%(0)$ & 30,835 & $<0,001$ \\
\hline 24. & $\begin{array}{l}\text { Przedstawienie wyników analizy za po- } \\
\text { mocą tabel, wykresów lub schematów }\end{array}$ & $54,1 \%(80)$ & $2 \%(3)$ & $45,5 \%(86)$ & $0,0 \%(0)$ & 154,932 & $<0,001$ \\
\hline 25. & Przedstawienie wniosków & $86,5 \%(128)$ & $57,4 \%(85)$ & $90,5 \%(171)$ & $62,4 \%(58)$ & 68,952 & $<0,001$ \\
\hline 26. & $\begin{array}{l}\text { Informacja dotycząca finansowania } \\
\text { i konfliktu interesów }\end{array}$ & $75,7 \%(112)$ & $6,8 \%(10)$ & $88,4 \%(167)$ & $9,7 \%(9)$ & 321,208 & $<0,001$ \\
\hline 27. & Podanie słów kluczowych & $100 \%(148)$ & $94,6 \%(140)$ & $67,7 \%(128)$ & $98,9 \%(92)$ & 104,854 & $<0,001$ \\
\hline 28. & $\begin{array}{l}\text { Wskazanie cytowanych źródeł w treści } \\
\text { pracy }\end{array}$ & $100 \%(148)$ & $79,8 \%(118)$ & $100 \%(189)$ & $98,9 \%(92)$ & 81,514 & $<0,001$ \\
\hline 29. & Zamieszczenie spisu piśmiennictwa & $100 \%(148)$ & $90,5 \%(134)$ & $100 \%(189)$ & $98,9 \%(92)$ & 32,338 & $<0,001$ \\
\hline 30. & $\begin{array}{l}\text { Liczba pozycji cytowanych w artykule: } \\
\text { wartość średnia (zakres) }\end{array}$ & $66,1(11-214)$ & $26,7(0-142)$ & $96,3(12-292)$ & $47,1(0-108)$ & $99,33^{*}$ & $<0,001$ \\
\hline
\end{tabular}

*Wartość F (ANOVA) 
sywano metodologię wyszukiwania prac źródłowych, bardzo rzadko opisywano sposób oceny i kryteria włączenia prac źródłowych do przeglądu, zdecydowana większość przeanalizowanych prac zawierała syntezę jakościową, a tylko 3 spośród 50 zawierały elementy syntezy ilościowej wyników prac źródłowych. Powtórzona dekadę później analiza pokazała, że niewiele się w tym zakresie zmieniło [12].

\section{Wnioski}

- Zaledwie co dwudziesty polskojęzyczny i co czwarty anglojęzyczny artykuł przeglądowy z zakresu medycyny estetycznej i kosmetologii zawiera informacje na temat metod doboru piśmiennictwa.

- Zdecydowana większość opublikowanych prac przeglądowych z zakresu medycyny estetycznej i kosmetologii ma charakter niesystematycznych i niestrukturyzowanych esejów opartych na niewielkiej liczbie dość przypadkowo dobranych prac źródłowych, co stawia pod znakiem zapytania ich wartość naukową.

\section{Piśmiennictwo}

1. Śpiewak R, Zabiegała A: Które polskie czasopisma z zakresu medycyny estetycznej i kosmetologii spełniają kryteria czasopisma naukowego? Estetol Med Kosmetol 2011;1(1):7-15.

2. Horvath AR, Pewsner D: Systematic reviews in laboratory medicine: principles, processes and practical considerations. Clin Chim Acta 2004;342(1-2):23-39.

3. Bettany-Saltikov J: Learning how to undertake a systematic review: Part 1. Nurs Stand 2010;24(50):47-55.

4. Thomas BH, Ciliska D, Dobbins M, Micucci S: A process for systematically reviewing the literature: providing the research evidence for public health nursing interventions. Worldviews Evid Based Nurs 2004;1(3):176-84.

5. Manriquez JJ: A highly sensitive search strategy for clinical trials in Literatura Latino Americana e do Caribe em Ciencias da Saude (LILACS) was developed. J Clin Epidemiol 2008;61(4):407-11.

6. Whiting P, Westwood M, Burke M, Sterne J, Glanville $\mathrm{J}$ : Systematic reviews of test accuracy should search a range of databases to identify primary studies. J Clin Epidemiol 2008;61(4):357-64.

7. Bettany-Saltikov J: Learning how to undertake a systematic review: Part 2. Nurs Stand 2010;24(51):4756.

8. Ng KH, Peh WC: Writing a systematic review. Singapore Med J 2010;51(5):362-6.

9. Gasparyan AY, Ayvazyan L, Blackmore H, Kitas GD: Writing a narrative biomedical review: considerations for authors, peer reviewers, and editors. Rheumatol Int 2011;31(11):1409-17.

10. Guilford WH: Teaching peer review and the process of scientific writing. Adv Physiol Educ 2001;25(1-4):167-75.

11. Mulrow CD: The medical review article: state of the science. Ann Intern Med 1987;106(3):485-8.
12. McAlister FA, Clark HD, van Walraven C, Straus SE, Lawson FM, Moher D, Mulrow CD: The medical review article revisited: has the science improved? Ann Intern Med 1999;131(12):947-51.

\section{Finansowanie i konflikt interesów}

Przedstawione badania i przygotowanie niniejszej publikacji zostało w całości sfinansowane $\mathrm{z}$ własnych środków autorów. Wszyscy autorzy deklarują niewystępowanie konfliktu interesów w odniesieniu do treści zawartych w niniejszej pracy.

\section{Adres do korespondencji}

dr hab. med. Radosław Śpiewak, profesor UJ

Zakład Dermatologii Doświadczalnej i Kosmetologii

Wydział Farmaceutyczny UJ

ul. Medyczna 9, 30-688 Kraków

Tel.: 1262058 30, Fax: 126205645

E-mail: spiewak.eu@gmail.com

Data złożenia: 2.08 .2012

Data akceptacji: 20.09.2012 